\title{
RESENHA - NAURIN, Elin; ROYED, Terry J.; THOMSON, Robert (Ed.). Party Mandates and Democracy: making, breaking, and keeping election pledges in twelve countries. New Comparative Politics. Ann Arbor: University of Michigan Press, 2019.'
}

REVIEW - NAURIN, Elin; ROYED, Terry J.; THOMSON, Robert (Ed.). Party Mandates and Democracy: making, breaking, and keeping election pledges in twelve countries. New Comparative Politics. Ann Arbor: University of Michigan Press, 2019.

\section{Simone Diniz²}

Devemos acreditar em promessas feitas por candidatos a cargos públicos durante as campanhas eleitorais? Embora haja exemplos marcantes de quebra de promessa, como a pronunciada pelo então candidato à presidente dos EUA em 1988, George H.W. Bush: "read my lips: no new taxes", as análises apresentadas em Party Mandates and Democracy indicam que nos casos analisados, a maioria das promessas são ao menos parcialmente cumpridas. Uma das principais conclusões da obra é que há forte ligação entre promessas de campanha e ações governamentais.

O livro apresenta não apenas análise quantitativa e estudos de caso das promessas de campanha expressas nos manifestos partidários de doze países - Alemanha, Áustria, Bulgária, Canadá, Espanha, Estados Unidos, Irlanda, Itália, Países Baixos, Portugal, Reino Unido e Suécia -, como também discorre sobre os elos entre promessas de campanha e o processo democrático. Para os autores, a democracia é um sistema que vincula cidadãos, governo e políticas

Esta resenha é um dos resultados do projeto "Promessas de Campanha Eleitoral e Agenda de Governo - Análise da Gestão dos ex-presidentes Fernando Henrique Cardoso e Luiz Inácio Lula da Silva", sediado na UFSCAR e financiado pela FAPESP (Projeto 2017-23525-2).

2 Doutora em Ciência Política pela Universidade de São Paulo (USP). Professora Associada na Universidade Federal de São Carlos (UFSCAR), São Carlos, SP, Brasil. E-mail: <simonediniz@ufscar.br> 
públicas. A mediação se dá por meio das eleições e, para eles, deve haver correspondência entre ações governamentais e os interesses dos cidadãos.

O debate teórico exposto no capítulo 1 se dá no âmbito da teoria do mandato, que tem como expoente o modelo proposto por Downs (2013). Centrado em dois atores - partidos políticos e eleitores - o autor assume que a principal motivação dos políticos é obter benefícios associados a cargos. São office seekers. Os eleitores, por sua vez, anseiam por políticas governamentais que correspondam aos seus interesses. São policy seekers. A máxima que decorre dessa formulação é bastante conhecida: partidos formulam policies para vencer eleições, e não o contrário: vencem eleições para formular policies.

Deriva ainda do modelo downsiano, o pressuposto de que os eleitores sufragarão o partido que apresentar propostas de políticas públicas mais próximas de suas preferências. O eleitor agiria de forma prospectiva, considerando as promessas anunciadas, e retrospectiva, quando avaliaria o grau de responsividade do governo em relação ao cumprimento das promessas. Sendo assim, há incentivos para que o partido governante promulgue as políticas anunciadas durante a campanha eleitoral.

No modelo de Downs também está implícita a visão de que, nos países que adotam o sistema proporcional, os elos de ligação entre as preferências de policies dos cidadãos e as ações governamentais seriam menos efetivas, pois aqueles que perderam a eleição exerceriam apenas o papel de oposição, enquanto aguardam a próxima rodada do jogo eleitoral. Ou ainda, que a participação de partidos em governos de coalizão atenderia muito mais à demanda dos partidos em colaborar com o partido vencedor, do que à representação de preferências dos eleitores no governo.

A argumentação desenvolvida por Downs é alvo de um intenso debate no âmbito da ciência política, conforme retratado por Naurin, Royed e Thomson (2019). Parte das críticas veem o modelo downsiano como um tipo ideal de democracia, apontando para o comportamento dos eleitores, partidos, governos e a natureza 
de ligação entre eles como irrealista, ou que eleitores são desinformados ou lhes falta opinião sobre vários temas (BARRY, 1970; ROBERTSON, 1976; BUDGE; FARLIE, 1977; MONROE, 1991; GROFMAN, 1993). Outro grupo de críticos da teoria do mandato aceitam o pressuposto de responsividade e accountability, mas ainda assim argumentam que pode haver outros incentivos para que os políticos se desviem das propostas de campanha. Uma ilustração típica dessa situação seria a ausência de informação completa sobre, por exemplo, a situação econômica e fiscal do país. Suponha-se que o governo anterior, competindo pela reeleição, tenha omitido informação. Neste caso, tanto o novo ocupante do Poder Executivo quanto os eleitores desconheciam o cenário real das contas públicas, delas tomando conhecimento apenas após assumirem o cargo. Neste cenário o novo governo depara-se com o dilema de desviar-se de suas promessas de campanha, formulando alternativas na busca pelo bom desempenho da situação econômica do país ou manter-se fiel às promessas feitas anteriormente, apesar de as circunstâncias terem mudado (MANIN; PRZEWORSKI; STOKES, 1999, p. 113).

Apesar das críticas à teoria do mandato, o argumento dos autores é que ela, ainda assim, pode ser utilizada como parâmetro para avaliação do regime democrático. Partidos políticos são organizações que selecionam e agregam temas e apresentam propostas ao eleitorado. $\mathrm{Na}$ ausência de uma demanda específica por uma política pública formulada pela maioria do eleitorado, os partidos devem ser inovadores e ativos, identificando temas e elaborando propostas que os cidadãos perceberão como relevantes e que estejam de acordo com os interesses partidários.

Além disso, ressaltam os autores, há importantes evidências na literatura que reforçam a validade da teoria do mandato, como: os eleitores confiam na ideologia como um dispositivo cognitivo que lhes permite deduzir as posições dos partidos em políticas mais específicas; os governos são punidos ou recompensados nas eleições pelas condições econômicas; os cidadãos detêm informação suficiente sobre política para avaliarem e votarem de maneira informada; os políticos são também policy seekers e formular promessas 
eleitorais específicas durante as campanhas os ajuda a aprovar suas propostas preferidas. Em suma, para os autores, os manifestos e as promessas de campanha podem e devem ser tomados como objeto empírico, porque servem a diferentes propósitos para os partidos. Neste sentido, resumidamente:

1) Os manifestos fornecem informação para os eleitores sobre o que os partidos farão, ofertando um caminho para avaliação prospectiva e retrospectiva do desempenho partidário;

2) As promessas de campanha auxiliam a mídia a exercer o papel de ligação entre cidadãos e partidos ao divulgar informação;

3) As promessas têm papel importante no interior das agremiações partidárias para a construção de consensos, especialmente nos partidos que contam com diferentes correntes ou tendências ideológicas;

4) As promessas não podem ser relegadas a segundo plano, especialmente em governos de coalizão, uma vez que o conteúdo expresso nos manifestos partidários poderá ser considerado para efeito da aceitação, ou não, de futuros parceiros na coalizão.

O livro também apresenta contribuição significativa aos interessados em desenvolver pesquisas sobre promessas de campanha. O capítulo 2 é uma espécie de guia metodológico onde os autores descrevem os procedimentos adotados sobre o que é ou pode ser considerado como promessas de campanha, propõe uma categorização das promessas (manutenção do status quo, expansão ou retração de programas governamentais, corte ou ampliação de gastos públicos etc.); dão indicações sobre como avaliar a execução das promessas, além de alertarem para a necessidade de realização de testes de confiabilidade e replicabilidade. Estes últimos não são aspectos menores. Pesquisas que adotam os manifestos partidários como objeto empírico assentam-se em análise de conteúdo, técnica bastante difundida na área de humanidades tanto nacional quanto internacionalmente, porém pouco atenta, apesar deste cenário estar passando por modificações no últimos anos, aos componentes desta metodologia que implicam em "verificar se diferentes codificadores 
têm a mesma compreensão sobre as variáveis de análise e se a codificação pode ser replicada por outrem, gerando resultados similares" (SAMPAIO; LYCARIÃO, 2018, p. 32).

De forma geral, os autores têm por objetivo verificar: se os partidos oferecem aos eleitores escolhas nas eleições em termos de promessas; em que extensão e sob quais condições as promessas de campanha são cumpridas; e que impacto arranjos políticos específicos (bicameralismo, federalismo, sistema de governo etc.) têm na manutenção e violação das promessas. Um dos pressupostos da literatura especializada, por exemplo, é que o sistema presidencialista, devido à separação de poderes e a sistemas partidários fragmentados e pouco coesos, não proporcionaria condições institucionais propícias para que os compromissos assumidos durante a campanha eleitoral sejam honrados (ROYED, 1996).

Os dois capítulos seguintes dedicam-se à análise quantitativa dos casos estudados. No capítulo 3, os autores comparam as promessas feitas em 57 eleições nos doze países selecionados. O primeiro movimento foi, partindo do pressuposto de que há incentivos para que todos os partidos façam promessas, verificar se foram apresentadas promessas passíveis de serem verificadas nas eleições estudadas. O segundo movimento seguiu no sentido de avaliar o possível impacto de algumas variáveis na quantidade e no conteúdo das promessas, a saber: a posição ideológica dos partidos; arranjo do sistema político (governo unitário ou de coalizão); e se o partido formulador era situacionista ou não.

Os resultados encontrados indicam que partidos políticos de diferentes matrizes ideológicas e em diferentes circunstâncias apresentam quantidade significativa de promessas, sendo indiferente, neste caso, se estão situados à esquerda ou à direita do espectro ideológico. Estar no exercício do mandato e disputando reeleição não apresentou variação significativa no volume de promessas formuladas, da mesma forma que também não houve associação entre governos de coalizão ou de partido único.

O capítulo 4 analisa comparativamente a execução das promessas. A expectativa confirmada era de que todos os partidos tentassem 
cumprir, ainda que parcialmente, suas promessas. Os resultados encontrados, levando-se em consideração o cumprimento total ou parcial das promessas e os partidos que disputaram a reeleição e mantiveram-se no governo, demonstram que o Reino Unido honrou $86 \%$ dos compromissos assumidos, seguido por Suécia e Portugal com 79\%, Espanha 72\%, Canadá 68\%, Alemanha e Estados Unidos 62\%, Países Baixos 57\%, Irlanda e Bulgária 52\%, Áustria 50\% e Itália 46\%. O restante do capítulo dedicou-se a verificar o impacto que outras variáveis institucionais podem ter no cumprimento das promessas. As evidências apresentadas são de que alguns arranjos afetam a probabilidade de realização das promessas. Por exemplo, governos de partido único majoritário reeleitos apresentaram desempenho de $74 \%$ no cumprimento das promessas, governos de partido único minoritário 66\%, governos de coalizão majoritárias $53 \%$ e de coalizão minoritária 59\%. Por outro lado, características institucionais como bicameralismo, federalismo e ser membro da Comunidade Europeia, entre outras características, não apresentaram efeito significativo no cumprimento das promessas.

Os demais capítulos (5 ao 16) dedicam-se aos estudos de casos e apresentam discussão mais detalhada sobre as características político-institucionais dos países e a relação com as promessas apresentadas e realizadas.

Party Mandates and Democracy não é a primeira obra a ser publicada sobre promessas de campanha. A pesquisa de Gerald Pomper (1968) sobre os Estados Unidos costuma ser indicada como pioneira no campo de análise das promessas de campanha, seguida de outras nas décadas seguintes. Entretanto, não é exagero afirmar que é apenas a partir do século XXI que esta área de pesquisa se tem desenvolvido, devido a avanços significativos de cunho metodológico e também na análise comparativa. Assim, nesse esteio, Party Mandates and Democracy apresenta contribuição significativa. 
No Brasil, não encontramos registro na bibliografia produzida internamente sobre promessas de campanha ${ }^{3}$. Encontramos apenas duas referências que se aproximam dessa abordagem: Tarouco et al. (2015) e Tarouco (2011). No primeiro caso. trata-se de artigo de caráter metodológico, onde os autores exploram as potencialidades da análise de conteúdo para mensurar preferências políticas por meio dos manifestos partidários. No segundo, embora a autora também analise os manifestos partidários, o principal objetivo é verificar se há diferenças significativas nos temas enfatizados pelos partidos políticos brasileiros. Ou seja, há lacuna na bibliografia da ciência política brasileira e a análise apresentada em Party Mandates and Democracy pode ser uma boa fonte de consulta e incentivo para os pesquisadores brasileiros adentrarem neste campo de pesquisa. Além disso, é importante e válido testar em que medida as conclusões apresentadas no livro se assemelham ou se sustentam no caso brasileiro.

\section{Referências}

BARRY, Brian. Sociologists, economists, and democracy. London: Macmillan, 1970.

BUDGE, Ian; FARLIE, David. Voting and party competition: a theoretical critique and synthesis applied to surveys from ten democracies. New York: Wiley, 1977.

DOWNS, Anthony. Uma teoria econômica da democracia. São Paulo: EDUSP, 2013.

GROFMAN, Bernard. Information, participation, and choice: an economic theory of democracy in perspective. Ann Arbor: University of Michigan Press, 1993.

MANIN, Bernard; PRZEWORSKI, Adam; STOKES, Susan. Eleições e representação. Lua Nova, n. 67, p. 105-138, 2006.

3 Consultamos a plataforma scielo.br e também os depositórios de teses e dissertações das principais universidades brasileiras, na área da ciência política (USP, UNICAMP, UNESP, UFPE, UFMG, UNB, URFGS, UFSCAR; UERJ; UFRJ). 
MONROE, Kristen R.. The economic approach to politics: a critical reassessment of the theory of rational action. New York: Harper Collins, 1991.

POMPER, Gerald. Elections in America: control and influence in democratic politics. New York: Dodd, Mead, 1968.

ROBERTSON, David. A theory of party competition. London: Wiley, 1976.

ROYED, Terry. Testing the mandate model in Britain and the United States: evidence from the Reagan and Thatcher eras. British Journal of Political Science, v. 26, n. 1, p. 45-80, 1996.

SAMPAIO, Rafael; LYCARIÃO, Diógenes. Eu quero acreditar! Da importância, formas de uso e limites dos testes de confiabilidade na análise de conteúdo. Revista de Sociologia e Política, v. 26, n. 66, p. 32-47, 2018.

TAROUCO, Gabriela; VIEIRA, Soraia; MADEIRA, Rafael. Mensuração de preferências políticas: análise de manifestos partidários. Revista Política Hoje, v. 24, p. 135-150, 2015. . Brazilian parties according to their manifestos: political identity and programmatic emphases. Brazilian Political Science Review, v. 5, n. 1, p. 54-76, 2011.

Recebido em 25 de maio de 2019

Aprovado em 26 de outubro de 2019 